\title{
Development of an ELISA Using a Recombinant P46-Like Lipoprotein for Diagnosis of Mycoplasma pulmonis Infection in Rodents
}

\author{
Atsushi ASANO ${ }^{1,2) *}$, Daisuke TORIGOE ${ }^{2)}$, Nobuya SASAKI ${ }^{2)}$ and Takashi AGUI ${ }^{2)}$ \\ ${ }^{1)}$ Laboratory of Veterinary Biochemistry, School of Veterinary Medicine, Faculty of Agriculture, Tottori University, Tottori 680-8553, Japan \\ ${ }^{2)}$ Laboratory of Laboratory Animal Science and Medicine, Department of Disease Control, Graduate School of Veterinary Medicine, \\ Hokkaido University, Sapporo, Hokkaido 060-0818, Japan
}

(Received 13 June 2013/Accepted 7 September 2013/Published online in J-STAGE 20 September 2013)

\begin{abstract}
Mycoplasma pulmonis is one of the most prevalent bacterial pathogens that infects laboratory mice and rats. To develop an $M$. pulmonis-specific antigen for serological diagnosis, we cloned the cDNA of P46-like lipoprotein (P46L), an M. pulmonis putative periplasmic protein. $\mathrm{P} 46 \mathrm{~L}$ is a homolog of $\mathrm{P} 46$, an M. hyopneumoniae antigen. We produced recombinant $\mathrm{P} 46 \mathrm{~L}$ fused to glutathione S-transferase (GST) in Escherichia coli. Immunoblot analysis revealed that sera from Mycoplasma-infected mice and rats contained anti-P46L antibodies. We developed an ELISA using the recombinant P46L-GST protein as an antigen. Thirteen of the 14 samples from rats naturally infected with M. pulmonis were determined to be positive according to the commercial ELISA (MONILISA Myco) and positive by our ELISA. Furthermore, 18/19 samples from mice experimentally infected with M. pulmonis were positive using our P46L-GST ELISA. In contrast, only $8 / 19$ samples from infected mice were positive by the commercial ELISA. Our results indicate that P46L-GST was an appropriate antigen for developing a serological test to determine M. pulmonis infection in laboratory mice and rats.

KEY WORDS: ELISA, Mycoplasma pulmonis, P46L.
\end{abstract}

doi: 10.1292/jvms.13-0308; J. Vet. Med. Sci. 76(2): 151-157, 2014

Mycoplasma pulmonis is a Gram-negative pathogenic bacterium that lacks a cell wall. Infection in rats and mice by this organism is known to cause pneumonia. The bacterium belongs to the class Mollicutes, order Mycoplasmatales, within the family Mycoplasmataceae. It is one of the most prevalent pathogenic agents in laboratory colonies of mice and rats $[16,32]$. Transmission is thought to be through intrauterine and aerosol routes between cage-mates and between adjacent cages $[14,31]$. Murine respiratory mycoplasmosis (MRM) is caused by M. pulmonis infections. MRM is usually subclinical, however, when clinical signs are occasionally observed, they can include dyspnea, snuffling, chattering, weight loss and reduced fertility $[2,23,24$, 30]. The severity of lesions in respiratory tissues and mortality due to MRM are dependent upon environmental factors and the strains of the host or organism [2, 3, 7-9]. As an example, $\mathrm{C} 57 \mathrm{BL} / 6$ mice are resistant to $M$. pulmonis infection with the severity of lung lesions in these mice much lower than those observed in $\mathrm{C} 3 \mathrm{H} / \mathrm{He}$ and $\mathrm{DBA} / 2$ mice $[3$, 8]. With respect to rats, Lewis rats are more susceptible to M. pulmonis than F344 rats [9]. Additionally, it has been found that $M$. pulmonis infection enhances the metastatic ability of melanoma cells in mice by inducing the release of proinflammatory cytokines [26]. To monitor M. pulmonis

*Correspondence to: Asano, A., Laboratory of Veterinary Biochemistry, School of Veterinary Medicine, Faculty of Agriculture, Tottori University, 4-101 Minami, Koyama-cho, Tottori 680-8553, Japan. e-mail: atasano@muses.tottori-u.ac.jp.

(C)2014 The Japanese Society of Veterinary Science

This is an open-access article distributed under the terms of the Creative Commons Attribution Non-Commercial No Derivatives (by-nc-nd) License $<$ http://creativecommons.org/licenses/by-nc-nd/3.0/>. infections in laboratories and animal facilities, an accurate and sensitive diagnostic test is necessary.

Serological assays that detect antibodies against pathogens are the most popular screening tests for diagnosing infections $[5,13]$ with ELISAs the most commonly used serological assays for detecting M. pulmonis infections [5, 13, 15]. To date, purified organisms have generally been used as antigens in serological tests for detecting antibodies against M. pulmonis [11]. However, obtaining a useful yield of $M y$ coplasma at the required purity requires time. In addition, cross reactivity between anti- $M$. pulmonis antibodies present in sera and antigens derived from other Mycoplasma was reported previously $[20,22]$. Therefore, the use of purified $M$. pulmonis-specific antigens, such as recombinant proteins or synthesized peptides, should result in more accurate, specific and sensitive serological assays. Membrane-associated lipoproteins derived from Mycoplasma have been reported to be antigenic and applicable to serological diagnosis. Recombinant P48 lipoproteins from both $M$. bovis and M. agalactiae have been used as ELISA antigens for the detection of antiP48 antibodies [25, 27]. The P46 and P65 lipoproteins from $M$. hyopneumoniae are known to be antigenic in swine [4], and an ELISA system using recombinant P46 was developed and used to detect $M$. hyopneumoniae infection [10].

In our study, we used a homolog of the $M$. hyopneumoniae P46 protein, P46-like lipoprotein (P46L), to assist in the development of an ELISA to determine $M$. pulmonis infection in laboratory rats and mice. Our protein of interest, P46L, consists of 460 amino acids and contains a periplasmic binding protein domain. We attempted to produce a recombinant P46L protein fused to glutathione S-transferase (GST; GSTP46L) in Escherichia coli, which could then be applied as an ELISA antigen. 


\section{MATERIALS AND METHODS}

Animals: C57BL/6N and DBA/2N mice were maintained in the animal facility of the Graduate School of Veterinary Medicine (Hokkaido University) until inoculation with $M$. pulmonis. Our animal facility was maintained at $23 \pm 2{ }^{\circ} \mathrm{C}$ and $50 \pm 10 \%$ relative humidity with a 12-hr light-dark cycle. 8 weeks old mice (C57BL/6N: $n=12, D B A / 2 N: n=7$ ) were anesthetized with ketamine/xylazine, collected blood samples from the tail vein and inoculated intranasally with 1 $\times 10^{2}$ or $1 \times 10^{5}$ CFUs of $M$. pulmonis m53 strain (a gift from Dr. Akira Takakura from the Central Institute for Experimental Animals, Japan). After 2 weeks, blood samples were obtained from the tail veins of inoculated mice anesthetized with ketamine/xylazine. Blood samples before inoculation (C57BL/6N: n=3, DBA/2N: n=3), confirmed negative for $M$. pulmonis infection by analysis with the commercial ELISA (described below), were used as controls. Inoculated mice were maintained in isolator cages with ventilation. The sera from rats (a congenic strain derived from Long-Evans, $\mathrm{LEH} / \mathrm{Hkv}-E d n r b^{s l}, 8-30$ weeks old $)$ that were normal $(\mathrm{n}=6)$ or naturally infected with $M$. pulmonis $(\mathrm{n}=14)$, confirmed whether negative or positive for M. pulmonis infection by analysis with the commercial ELISA, were obtained for routine screening according to the guidelines of the Institutional Animal Care and Use Committee (IACUC) of the Graduate School of Veterinary Medicine (Hokkaido University). Animal experiments were conducted according to the Regulations for the Care and Use of Laboratory Animals of Hokkaido University. Our experimental protocol was approved by the IACUC of Hokkaido University.

cDNA cloning of P46L proteins: The M. pulmonis m53 strain was grown in PPLO broth (BD, Franklin Lakes, NJ, U.S.A.) with $20 \%$ heat-inactivated calf serum (Life Technologies, Carlsbad, CA, U.S.A.), 2.5\% fresh yeast extract, $0.05 \%$ thallium acetate (Wako, Tokyo, Japan) and 1,000 U/ $\mathrm{m} l$ penicillin $\mathrm{G}$ (Wako) at $37^{\circ} \mathrm{C}$ for 7 days and then harvested by centrifugation. Total RNA was isolated by TRIzol reagent (Life Technologies). Synthesis of first-strand cDNA was performed in a $10 \mu \mathrm{l}$ reaction mixture containing $0.5 \mu \mathrm{g}$ of $M$. pulmonis total RNA, $50 \mathrm{U}$ of reverse transcriptase (ReverTra
Ace, Toyobo, Tokyo, Japan), $1 \mu l$ of $2.5 \mathrm{mM}$ deoxyribonucleoside triphosphates (dNTPs) and $1 \mu l$ of $10 \mu \mathrm{M}$ random hexamer oligonucleotides. Regions $1-5$ of P46L cDNA (Fig. $2 \mathrm{~A})$ were amplified by $\mathrm{PCR}$ in a $25 \mu l$ reaction containing $1 \mu l$ of reaction solution of reverse transcription, $2.5 \mathrm{U}$ of Taq polymerase (ExTaq, Takara, Tokyo, Japan), $1 \mu l$ of 2.5 $\mathrm{mM}$ dNTPs and $1 \mu \mathrm{l}$ of PCR primers (10 $\mu \mathrm{M}$; Fig. 2A). The thermal cycling profile was $94^{\circ} \mathrm{C}$ for $30 \mathrm{sec}, 55^{\circ} \mathrm{C}$ for $30 \mathrm{sec}$ and $72^{\circ} \mathrm{C}$ for $30 \mathrm{sec}$ over 30 cycles. Overlap extension PCR for amplification of cDNA encoding the full-length $\mathrm{P} 46 \mathrm{~L}$ protein was performed in a $25 \mu l$ reaction containing $1 \mu l$ of PCR primers (10 $\mu \mathrm{M}$; Fig. $2 \mathrm{~B}), 0.1 \mathrm{ng}$ of each purified PCR product (Fig. 2A) and $2.5 \mathrm{U}$ of ExTaq polymerase. The thermal cycling profile was $94^{\circ} \mathrm{C}$ for $30 \mathrm{sec}, 55^{\circ} \mathrm{C}$ for $30 \mathrm{sec}$ and $72^{\circ} \mathrm{C}$ for $1 \mathrm{~min}$ over 30 cycles. The nucleotide sequence of all primers and their binding positions are based on the sequence of M. pulmonis (GenBank Accession Number NC 002771) as listed in Table 1. The lowercase small letters in the sequences represent mutated nucleotides. DNA fragments obtained by PCR were cloned into the pGEM-T Easy vector (Promega, Madison, WI, U.S.A.) and confirmed by sequencing with an ABI PRISM 377 DNA sequencer (Applied Biosystems, Foster City, CA, U.S.A.).

Expression and purification of recombinant GST-P46L proteins: P46L cDNA, containing TGG codons that had been substituted for TGA, was cloned into pGEX-6P-2 (GE Healthcare Bio-Science, Piscataway, NJ, U.S.A.) between the BamHI and EcoRI recognition sites. E. coli BL21 (GE Healthcare, Buckinghamshire, U.K.) was used for transformation of the cloned plasmids with transformed cells grown in LB broth. Expression of proteins was induced through the addition of $1 \mathrm{mM}$ isopropyl $\beta$-D-1-thiogalactopyranoside (IPTG). Cultures were then left to grow for $4 \mathrm{hr}$, before they were harvested by centrifugation. The resulting cell pellet was resuspended in PBS containing 1\% Triton X-100 and $1 \%$ Tween 20, sonicated and centrifuged. Recombinant GST-P46L in the supernatant was isolated by batch purification with glutathione-Sepharose 4B beads (GE Healthcare) according to the manufacturer's protocol. Lysates of transformed $E$. coli treated with IPTG and purified recombinant proteins were analyzed by SDS-PAGE and visualized by

Table 1. Oligonucleotide primers used in the cloning of M. pulmonis $\mathrm{P} 46 \mathrm{~L}$

\begin{tabular}{llc}
\hline \multicolumn{1}{c}{ Primer name } & \multicolumn{1}{c}{ Sequence $\left(5^{\prime} \rightarrow 3^{\prime}\right)^{*}$} & $\begin{array}{c}\text { Nucleotide position in the } \text { M. pulmonis } \\
\text { sequence (NC_002771) }\end{array}$ \\
\hline MP-p46L-F1 & CTG GGA TCC TTG AAA TGg GTT TAT ATG & $401976-402093$ \\
MP-p46L-Tr & CTG GGA TCC TCG GGT TCA ACA GCA TCT & $402096-402113$ \\
MP-p46L-m01F & AAT CAA AGA TGg GTA GAG AC & $402192-402211$ \\
MP-p46L-m01R & GTC TCT ACc CAT CTT TGA TT & $402211-402192$ \\
MP-p46L-m02F & ACA ATT GgT ATG TTG CCT TC & $402463-402482$ \\
MP-p46L-m02R & GAA GGC AAC ATA cCA ATT GT & $402482-402463$ \\
MP-p46L-m03F & AGC AAA CTG gAA CTA TTC AC & $402836-402855$ \\
MP-p46L-m03R & GTG AAT AGT TcC AGT TTG CT & $402855-402855$ \\
MP-p46L-m04F & GAA GAC TGg AAA ATA GCA GC & $403089-403108$ \\
MP-p46L-m04R & GCT GCT ATT TTc CAG TCT TC & $403108-403089$ \\
MP-p46L-R1 & CTA TGA TTC TTT CTT GAA AA & $403358-403339$ \\
\hline
\end{tabular}

*Lowercase letters in the primer sequences indicate substituted nucleotides for site-directed mutagenesis. 
Coomassie brilliant blue R-250-staining.

Immunoblot analysis of P46L-GST: Transformed E. coli lysate $(10 \mu \mathrm{g})$ and recombinant protein $(1 \mu \mathrm{g})$ were separated by SDS-PAGE using $10 \%$ polyacrylamide gels and transferred to polyvinylidene difluoride (PVDF) membranes (Immobilon-P, Millipore, Billerica, MA, U.S.A.) with a semi-dry blotter (Bio-Rad Laboratories, Hercules, CA, U.S.A.). Membranes were incubated in blocking buffer $\{5 \%$ skim milk in PBS-T (137 mM NaCl, $81 \mathrm{mM} \mathrm{Na}_{2} \mathrm{HPO}_{4}, 15$ $\mathrm{mM} \mathrm{KH} \mathrm{PO}_{4}, 27 \mathrm{mM} \mathrm{KCl}$ and $0.1 \%$ Tween 20 ) $\}$ at room temperature for $1 \mathrm{hr}$, rinsed with PBS-T and then incubated at room temperature for $1 \mathrm{hr}$ in blocking buffer with diluted serum $(1: 1,000)$ from $M$. pulmonis-positive mice diagnosed with a commercial ELISA kit (MONILISA Myco, Wakamoto Pharmaceutical Co., Ltd., Tokyo, Japan). Membranes were washed with PBS-T and incubated in blocking buffer containing horseradish peroxidase (HRP)-conjugated antimouse IgG (1:10,000; GE Healthcare Bio-Science) at room temperature for $1 \mathrm{hr}$. They were then washed with PBS-T and treated with ECL Plus reagents (GE Healthcare BioScience). Detection of chemiluminescence was conducted with an LAS-3000 imaging system (Fujifilm, Tokyo, Japan).

ELISA: The commercial MONILISA Myco ELISA kit was used to detect antibodies against $M$. pulmonis in serum samples according to the manufacturer's instructions. Serum samples $(200 \mu l)$ were diluted 1:40, before they were applied to the ELISA. Determination of positive and negative samples was conducted by macroscopically comparing the color reaction in wells with known positive control samples within the assay. Positive control sera within the commercial ELISA kit yielded OD values of $0.3-0.4$ at $492 \mathrm{~nm}$ [18]. For the ELISA we developed, a $200 \mu l$ aliquot of $1 \mu \mathrm{g} / \mathrm{m} l$ affinity-purified P46L-GST in $50 \mathrm{mM}$ sodium carbonatebicarbonate buffer ( $\mathrm{pH}$ 9.6) was added to each well of a 96-well plate and incubated at $4{ }^{\circ} \mathrm{C}$ overnight. Wells were washed three times with PBS-T and incubated with $200 \mu l$ of ELISA blocking buffer ( $1 \%$ bovine serum albumin in PBS$\mathrm{T})$ at $37^{\circ} \mathrm{C}$ for $1 \mathrm{hr}$. Wells were washed a further three times with PBS-T, before $200 \mu l$ of mouse sera (diluted 1:160 in ELISA blocking buffer) or $200 \mu \mathrm{l}$ of rat sera (diluted 1:200 in ELISA blocking buffer) was added and incubated at $37^{\circ} \mathrm{C}$ for $1 \mathrm{hr}$. Wells were again washed three times with PBS-T, and an aliquot $(200 \mu l)$ of HRP-conjugated anti-mouse IgG (1:10,000; GE Healthcare Bio-Science) in ELISA blocking buffer or HRP-conjugated anti-rat IgG (1:20,000; SigmaAldrich, St. Louis, MO, U.S.A.) was added to each well and incubated at $37^{\circ} \mathrm{C}$ for $1 \mathrm{hr}$. Wells were again washed three times with PBS-T, before $1.5 \mathrm{mg} / \mathrm{ml} o$-phenylenediamine with $0.01 \% \mathrm{H}_{2} \mathrm{O}_{2}(200 \mu l)$ was added to each well and incubated at $37^{\circ} \mathrm{C}$ for $10 \mathrm{~min}$. The reaction was stopped through the addition of $3 \mathrm{M} \mathrm{H}_{2} \mathrm{SO}_{4}(50 \mu l)$, and the $\mathrm{OD}$ at $450 \mathrm{~nm}$ for each well was measured with a Model 680 microplate reader (Bio-Rad Laboratories).

Statistics: For statistical analyses, Student's $t$-test, oneway analysis of variance (ANOVA) with Tukey's post-hoc test and Fisher's exact test were performed using GraphPad Prism 5.0 (GraphPad software, La Jolla, CA, U.S.A.).

\section{RESULTS}

Cloning P46L from M. pulmonis: The P46L protein is known to be encoded by the MYPU 3430 gene (NCBI Gene ID: 911636). The protein comprises 460 amino acids with a predicted molecular weight of $50.6 \mathrm{kDa}$. The amino acid sequence of $\mathrm{P} 46 \mathrm{~L}$ was found to be $28 \%$ identical to that for M. hyopneumoniae P46 (Fig. 1). Protein motif scanning using InterProScan [33] revealed that P46L was predicted to contain a prokaryotic membrane lipid attachment site [12] at positions 1-31 (Fig. 1) and a periplasmic binding protein domain at positions 64-390 (Fig. 1) [21].

For the entire coding region of the $\mathrm{P} 46 \mathrm{~L}$ gene (nucleotides 401,976-403,358; GenBank Accession No. NC_002711), there were five TGA codons that corresponded to tryptophan in Mycoplasma, however, these are termination codons in mammals and other bacteria (Fig. 2A). These five TGA codons were altered to TGG. Cloning of mutated P46L cDNA was conducted using site-directed mutagenesis and overlap extension PCR. The P46L coding sequence was divided into five fragments (Fig. 2A), and each cDNA fragment was amplified by RT-PCR using the primers presented in Table 1. We then amplified the entire coding sequence by overlap extension PCR using all five amplicons as templates (Fig. 2B). This PCR product was cloned, and we confirmed by sequencing that it corresponded to the entire P46L coding sequence with five TGG codons in place of the TGA codons (data not shown).

Expression and purification of P46L-GST: The P46L cDNA was successfully cloned into pGEX-6P between the $B a m \mathrm{HI}$ and EcoRI sites and then transformed into E. coli to enable expression of a recombinant protein. Protein samples

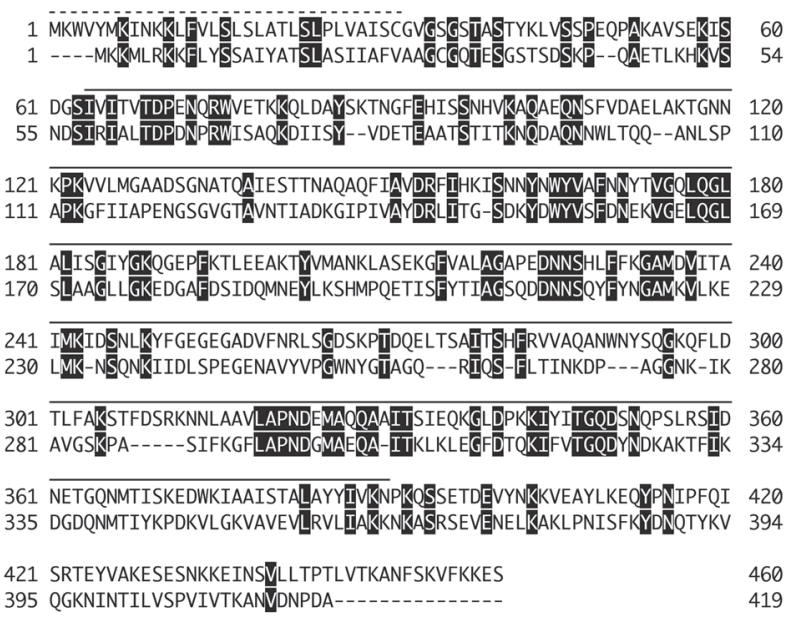

Fig. 1. Amino acid sequence alignment for M. pulmonis P46L (upper sequence) and M. pneumoniae P46 (lower sequence). Identical amino acid residues are highlighted with black boxes. The dashed lines indicate gaps in the sequence alignment. The putative prokaryotic membrane lipid attachment site is indicated by the dotted line. A putative periplasmic binding protein domain is indicated by the solid line. P46 accession number, BAA04085; P46L, NP_326174. 
A

M. pulmonis P46L cDNA

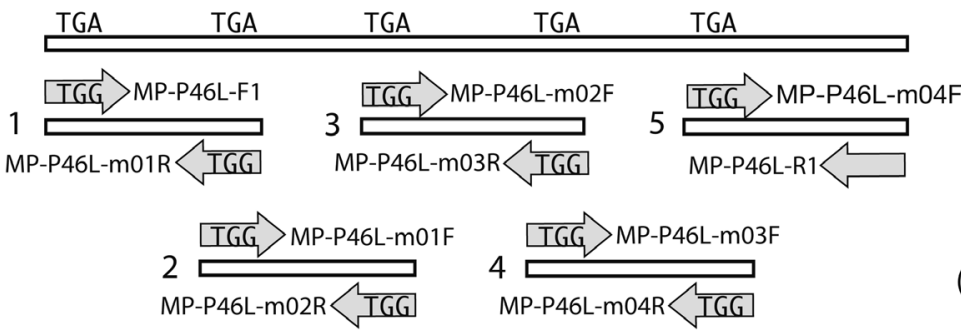

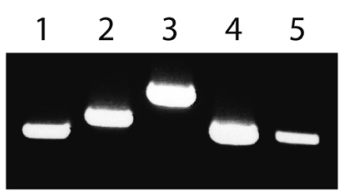

B

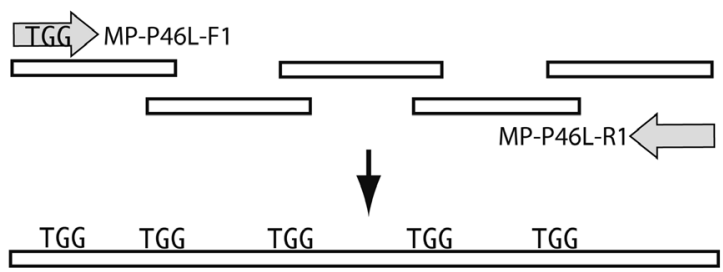

(bp) 246293395275272

Fig. 2. Amplification of mutated P46L cDNA using site-directed mutagenesis and overlap extension PCR. (A) Overlapping primers containing TGG mutations (left panel and Table 1) were used for amplification of P46L cDNA fragments 1-5. Amplicons were electrophoresed on agarose gels, stained with ethidium bromide and visualized using UV light (right panel). (B) P46L cDNA was amplified by overlapping PCR using purified PCR products obtained in (A) and the primers shown in the left panel. The P46L cDNA PCR product (1,391 bp) can be seen in the right panel.

from the lysates of transformed E. coli and purified P46LGST were analyzed by SDS-PAGE (Fig. 3A). A strong band consistent with $77.5 \mathrm{kDa}$ was observed; this was around the expected size for P46L-GST. We performed immunoblot analysis of protein samples using mouse sera from $M$. pulmonis-infected mice (Fig. 3B). An immunoreactive band was observed at the same position as that for the purified P46L-GST seen in Fig. 3A. We also observed the same band when sera from $M$. pulmonis-infected rats were employed (data not shown).

ELISA detection of anti-M. pulmonis antibodies: When we analyzed $M$. pulmonis-positive mouse serum by ELISA using P46L-GST, the OD at $450 \mathrm{~nm}$ for samples diluted 1:80 was higher than the ODs at other dilutions. In contrast, OD values for control serum were similar to those when serum was absent and did not vary across dilutions (Fig. 4A). Similar ELISA results were obtained using rat sera (Fig. 4B). The OD values were almost constant among samples diluted 1:100-1:800 and then decreased at higher dilutions. We analyzed the same rat serum samples from Fig. 4B using a commercial ELISA (data not shown). In contrast to our ELISA, OD values for samples diluted 1:320 decreased to one-third the level of that observed for the 1:40 dilution.

Evaluation of the developed ELISA as a suitable diagnostic tool for M. pulmonis infection: The range in OD values for control rat sera was $0.075-0.152$ (Fig. 5A), whereas that for sera from rats naturally infected with $M$. pulmonis rats was $0.109-0.620$ (Fig. 5A). Our determined means and standard deviations (SDs) were 0.114 and 0.028 , respectively, for control rats and 0.444 and 0.147 for infected rats. The

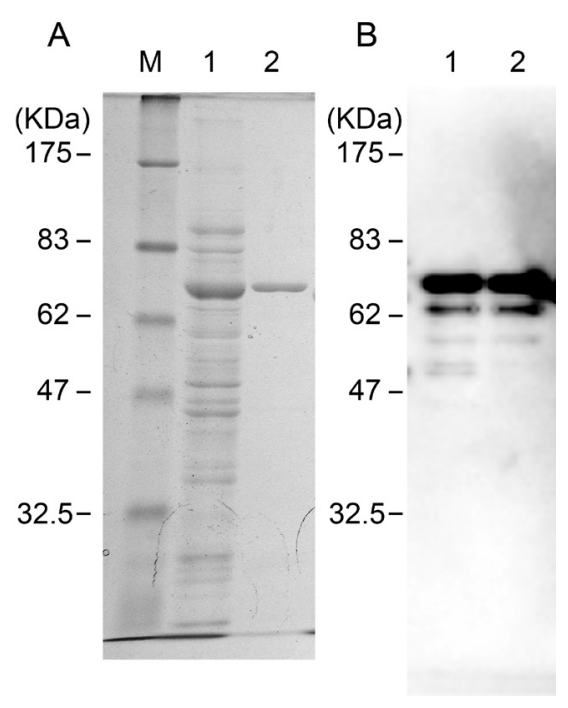

Fig. 3. Recombinant P46L-GST expressed in E. coli and its antigenicity. (A) SDS-PAGE stained with Coomassie brilliant blue R-250. Lane M, size marker; 1, sample of $E$. coli cell lysate after induction with IPTG $(10 \mu \mathrm{g}) ; 2$, affinity-purified P46L-GST $(1 \mu \mathrm{g})$. (B) Immunoblot analysis of recombinant P46L using serum from experimentally M. pulmonis-infected C57BL/6N mice. A typical blot taken from five independent experiments. Lane 1, sample of $E$. coli cell lysate following IPTG induction $(10 \mu \mathrm{g}) ; 2$, affinitypurified P46L-GST $(1 \mu \mathrm{g})$. 
A
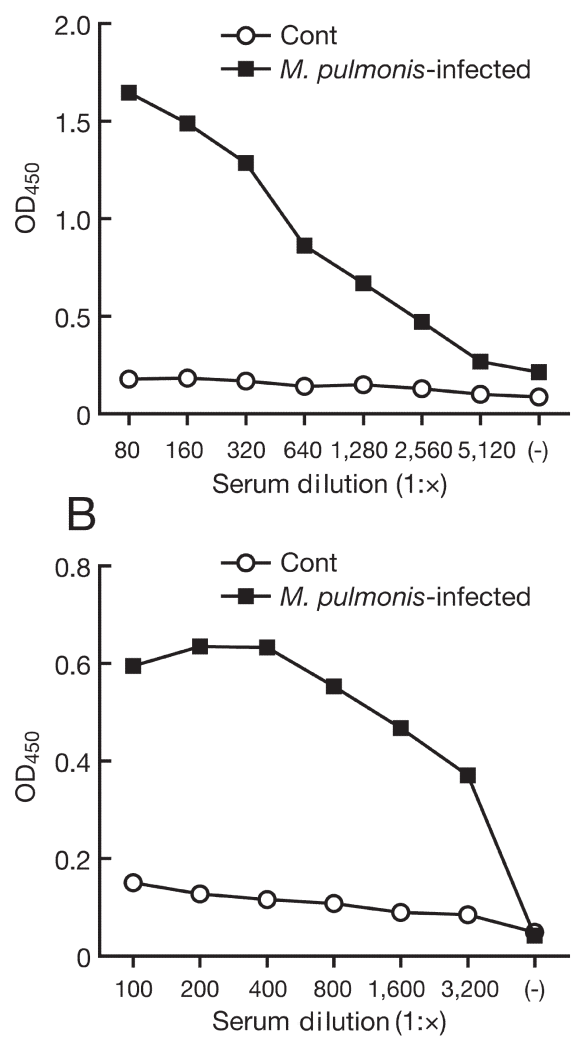

Fig. 4. ELISA using P46L-GST as the antigen. Sera from mice (A) and rats (B), used in Fig. 5, were diluted and used to test the ELISA we developed. Open circles indicate serum samples from control animals, and shaded squares are indicative of serum samples from M. pulmonis-infected animals. (-) indicates a non-serum sample. The plot is representative of data from two independent experiments.

mean OD value for infected rats was significantly higher than that for control rats using Student's $t$-test.

For mice, the range in OD values was $0.141-0.236$ for control sera (Fig. 5B). For mice experimentally infected with M. pulmonis but where antibodies against M. pulmonis were not detected in sera using a commercial ELISA, the range was $0.194-0.437$ (Fig. 5B). The range in OD values was $0.287-0.634$ for sera from mice that were experimentally
A

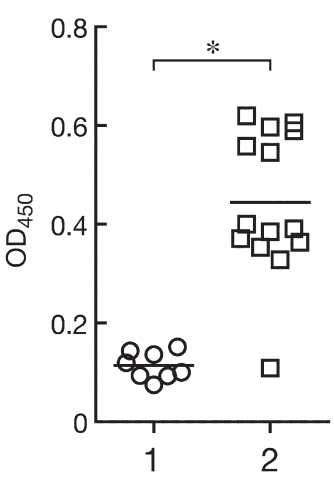

Fig. 5. Evaluation of the P46L-GST ELISA. The solid lines indicate the mean OD values. (A) 1, sera from control (uninfected) rats; 2, sera from rats naturally infected with $M$. pulmonis and diagnosed as Mycoplasma-positive using the commercial ELISA. $* P<0.05$ vs. control using Student's $t$-test. (B) 1 , sera from control (uninfected) mice; 2, sera from mice experimentally infected with M. pulmonis and diagnosed as negative for $M$. pulmonis infection using the commercial ELISA; 3, sera from mice experimentally infected with $M$. pulmonis and diagnosed as positive for $M$. pulmonis infection using the commercial ELISA. ${ }^{*} P<0.05$ vs. control using ANOVA with Tukey's post-hoc test.

infected with $M$. pulmonis and where antibodies could be detected using the commercial ELISA (Fig. 5B). The determined means and SDs were 0.190 and 0.033 , respectively, for controls, 0.349 and 0.076 for infected but ELISA-negative samples and 0.384 and 0.127 for infected and ELISApositive samples. The mean OD values for infected mice were significantly higher than those for control mice.

For our P46L-GST ELISA, we determined the cutoff OD value (mean $+2 \mathrm{SD}$ of controls) for an M. pulmonispositive rat sample to be 0.170 and for an M. pulmonispositive mouse sample to be 0.255 . Based on these cutoff values, we evaluated serum samples used in Fig. 5 (Table 2). All control samples were diagnosed as negative for $M$. pulmonis infection. Thirteen of the fourteen samples from rats naturally infected with $M$. pulmonis were determined to be positive according to the commercial ELISA and positive by our ELISA. Furthermore, 18/19 samples from mice experimentally infected with $M$. pulmonis were positive using our P46L-GST ELISA. In contrast, only 8/19 samples from infected mice were positive by the commercial ELISA.

Table 2. Evaluation of serum samples using the P46L-GST ELISA

\begin{tabular}{lcc}
\hline & \multicolumn{2}{c}{ Positive samples/total samples } \\
& Commercial ELISA & P46L-GST ELISA \\
\hline Control rats & $0 / 8$ & $0 / 8$ \\
Rats naturally infected with M. pulmonis & $14 / 14$ & $13 / 14$ \\
\hline Control mice & $0 / 6$ & $0 / 6$ \\
Mice experimentally infected with $M$. pulmonis & $8 / 19$ & $18 / 19^{*}$ \\
\hline
\end{tabular}

$* P<0.05$ vs. commercial ELISA using Fisher's exact test. 
For the serum samples from infected mice, the frequency of positives was significantly different between the ELISAs.

\section{DISCUSSION}

M. pulmonis is a prevalent pathogenic microorganism in laboratory colonies of mice and rats and is known to cause murine respiratory mycoplasmosis [2, 32]. It is important to monitor for M. pulmonis infections so that the health of rodent colonies at important animal facilities can be maintained at the highest levels. Serological tests, such as ELISAs, are the most common methods for diagnosing Mycoplasma infections $[5,13]$. In the present study, we developed an ELISA using a recombinant P46L protein as the antigen and found it to be sufficient for diagnosis of $M$. pulmonis infection comparing with a commercially available ELISA.

P46 is an antigenic protein of M. hyopneumoniae [4] with a recombinant form of P46 previously used as an ELISA antigen [10]. We hypothesized that antigenic proteins derived from $M$. pulmonis would also be useful for serological diagnosis in rodents. Using a BLAST search against a protein sequence database, we identified that $\mathrm{P} 46 \mathrm{~L}$, a homolog of $\mathrm{P} 46$ in $M$. pulmonis, might be an appropriate protein that could be used as an ELISA antigen. We were unable to determine any other M. pulmonis proteins that were homologous to P46 (data not shown). P46L is predicted to be a lipoprotein, as it contains motifs similar to those found in prokaryotic membrane lipid attachment sites (amino acids 1-31). Additionally, P46L has a putative periplasmic binding domain at positions 64-390. The periplasmic binding domain is frequently seen in the component of the ATP binding cassette-type sugar transport systems in various bacteria [1, $6,28]$. Therefore, P46L may act as a component of a sugar transporter complex in M. pulmonis.

Our results show that P46L-GST was highly expressed in E. coli (Fig. 3) and could be successfully purified by affinity chromatography. Furthermore, this protein was strongly reactive to sera from $M$. pulmonis-infected mice and rats; therefore, we believe that P46L-GST is an appropriate antigen for serological diagnosis of $M$. pulmonis infections. Using purified P46L-GST, we developed an ELISA and compared it with a commercial ELISA. In the commercial ELISA we tested, the antigens used were untreated but cultured bacterial cells [11]. Our findings show that the P46LGST ELISA was able to detect antibodies against P46L-GST (Fig. 4) in sera from infected mice and rats. The mean OD values attributed to sera from $M$. pulmonis-infected mice and rats were significantly higher than those from respective controls (Fig. 5). The commercial ELISA we used in this study is a standard test for diagnosis of $M$. pulmonis infection in laboratory mice and rats by International Council for Laboratory Animal Science Monitoring Center in Japan [11, 13]. Our results indicate that the P46L-GST ELISA we have developed is appropriate for determining the serological state of sera from M. pulmonis-infected mice and rats. However, we did observe one discrepancy involving a serum sample from a rat. According to the commercial ELISA used in this study, the sample was considered Mycoplasma-positive, yet our P46L-GST ELISA indicated that the sample should be classed as Mycoplasma-negative. (Fig. 5A and Table 2). This is a strong indicator that our ELISA requires further validation and improvement. The expression of V-1 lipoproteins is regulated by site-specific genomic DNA inversions of the $v s a$ genes that cause the phase-variable production of different V-1 proteins in individual isolates of M. pulmonis [29]. Furthermore, polymorphisms of the variable lipoprotein and hemagglutinin gene $(v \operatorname{lh} A)$ are seen among the strains of $M$. synoviae [17]. P46L gene was found in M. pulmonis strains UAB CTIP (MYPU_3430 gene in NCBI genome database) and $\mathrm{m} 53$ (this study). To validate our ELISA, it is important to examine whether P46L gene exists and expresses in various strains of $M$. pulmonis, and the gene product is antigenic in mice and rats. In addition, cross-reactivity of GST-P46L to sera from rats and mice infected with various strains of M. pulmonis or Mycoplasma spp. is necessary to investigate. A previous report revealed that $M$. pulmonis antigen had cross-reactivity against $M$. arthritidis antisera [22]. By analysis of protein BLAST search, we found P46L-like proteins showing 30-36\% homology in M. hyopneumoniae, M. alligatoris, M. crocodyli, M. flocculare, M. mobile and M. hyorhinis, but not in M. arthritidis and other Mycoplasma (data not shown). Therefore, it is expected that GST-P46L protein does not cross-react with $M$. arthritidis antisera. Moreover, PCR-based method may be helpful to detect $M$. pulmonis-specific infection [19]. As stated previously, the antigen used in the commercial ELISA we tested was the M. pulmonis organism itself [11]. Propagation and purification of a sufficient amount of Mycoplasma for this purpose are time-consuming. In contrast, recombinant proteins, such as P46L-GST, can be mass-produced, demonstrate greater stability and are easier to use. This point gives our ELISA an advantage over the commercial ELISA used in this study.

In summary, we expressed and purified M. pulmonis $\mathrm{P} 46 \mathrm{~L}$, a putative periplasmic lipoprotein homologous to $\mathrm{P} 46$ from $M$. hyopneumoniae antigenic protein. The recombinant protein we expressed was fused to GST, which allowed for easy purification. The antigenicity of the protein was confirmed in mice and rats infected with M. pulmonis. Application of the recombinant fusion protein as an ELISA antigen was found to be appropriate in the detection of anti-P46L antibodies. We believe that the ELISA we have developed can, and should be, successfully deployed for the serological diagnosis of $M$. pulmonis infection in mice and rats colonies at animal facilities.

\section{REFERENCES}

1. Altenberg, G. A. 2003. The engine of ABC proteins. News Physiol. Sci. 18: 191-195. [Medline]

2. Baker, D. G. 1998. Natural pathogens of laboratory mice, rats, and rabbits and their effects on research. Clin. Microbiol. Rev. 11: 231-266. [Medline]

3. Cartner, S. C., Simecka, J. W., Briles, D. E., Cassell, G. H. and Lindsey, J. R. 1996. Resistance to mycoplasmal lung disease in mice is a complex genetic trait. Infect. Immun. 64: 5326-5331. [Medline]

4. Cheikh Saad Bouh, K., Shareck, F. and Dea, S. 2003. Monoclo- 
nal antibodies to Escherichia coli-expressed P46 and P65 membranous proteins for specific immunodetection of Mycoplasma hyopneumoniae in lungs of infected pigs. Clin. Diagn. Lab. Immunol. 10: 459-468. [Medline]

5. Compton, S. R. and Riley, L. K. 2001. Detection of infectious agents in laboratory rodents: traditional and molecular techniques. Comp. Med. 51: 113-119. [Medline]

6. Davidson, A. L., Dassa, E., Orelle, C. and Chen, J. 2008. Structure, function, and evolution of bacterial ATP-binding cassette systems. Microbiol. Mol. Biol. Rev. 72: 317-364. [Medline] [CrossRef]

7. Davidson, M. K., Lindsey, J. R., Parker, R. F., Tully, J. G. and Cassell, G. H. 1988. Differences in virulence for mice among strains of Mycoplasma pulmonis. Infect. Immun. 56: 2156-2162. [Medline]

8. Davis, J. K., Parker, R., White, H., Dziedzic, D., Taylor, G., Davidson, M., Cox, N. and Cassell, G. 1985. Strain differences in susceptibility to murine respiratory mycoplasmosis in C57BL/6 and $\mathrm{C} 3 \mathrm{H} / \mathrm{HeN}$ mice. Infect. Immun. 50: 647-654. [Medline]

9. Davis, J. K., Simecka, J. W., Williamson, J. S., Ross, S. E., Juliana, M. M., Thorp, R. B. and Cassell, G. H. 1985. Nonspecific lymphocyte responses in F344 and LEW rats: susceptibility to murine respiratory mycoplasmosis and examination of cellular basis for strain differences. Infect. Immun. 49: 152-158. [Medline]

10. Futo, S., Seto, Y., Okada, M., Sato, S., Suzuki, T., Kawai, K., Imada, Y. and Mori, Y. 1995. Recombinant 46-kilodalton surface antigen (P46) of Mycoplasma hyopneumoniae expressed in Escherichia coli can be used for early specific diagnosis of mycoplasmal pneumonia of swine by enzyme-linked immunosorbent assay. J. Clin. Microbiol. 33: 680-683. [Medline]

11. Goto, K., Hayashimoto, N., Ishida, T., Takakura, A. and Kagiyama, N. 2009. First trial in the developmental phase of the "performance evaluation program" based on the ICLAS animal quality network program: self-assessment of microbiological monitoring methods using test samples supplied by ICLAS. Exp. Anim. 58: 47-52. [Medline] [CrossRef]

12. Hayashi, S. and Wu, H. C. 1990. Lipoproteins in bacteria. $J$. Bioenerg. Biomembr. 22: 451-471. [Medline] [CrossRef]

13. Hayashimoto, N., Morita, H., Ishida, T., Yasuda, M., Kameda, S., Uchida, R., Tanaka, M., Ozawa, M., Sato, A., Takakura, A., Itoh, T. and Kagiyama, N. 2013. Current microbiological status of laboratory mice and rats in experimental facilities in Japan. Exp. Anim. 62: 41-48. [Medline] [CrossRef]

14. Homberger, F. R. and Thomann, P. 1994. Transmission of murine viruses and mycoplasma in laboratory mouse colonies with respect to housing conditions. Lab. Anim. 28: 113-120. [Medline] [CrossRef]

15. Horowitz, S. A. and Cassell, G. H. 1978. Detection of antibodies to Mycoplasma pulmonis by an enzyme-linked immunosorbent assay. Infect. Immun. 22: 161-170. [Medline]

16. Jacoby, R. O. and Lindsey, J. R. 1997. Health care for research animals is essential and affordable. FASEB J. 11: 609-614. [Medline]

17. Jeffery, N., Gasser, R. B., Steer, P. A. and Noormohammadi, A. H. 2007. Classification of Mycoplasma synoviae strains using single-strand conformation polymorphism and high-resolution melting-curve analysis of the vlhA gene single-copy region. Microbiology 153: 2679-2688. [Medline] [CrossRef]

18. Kagiyama, N., Takakura, A., Terada, E., Sakurai, Y. and Suzuki, H. 1990. Studies on the development of an ELISA kit for microbiological monitoring. 1. Evaluation of the reliability of the prototype kit by field tests. Exp. Anim. 39: 89-96. [Medline]

19. Kim, D. J., Park, J. H., Seok, S. H., Cho, S. A., Baek, M. W., Lee, H. Y., Yang, K. H., Jang, D. D., Han, B. S. and Park, J. H. 2005. Differential identification of mycoplasma pulmonis and M. arthritidis using PCR-based RFLP. Exp. Anim. 54: 359-362. [Medline] [CrossRef]

20. Kobayasi, N., Terada, E., Kunita, S., Sakurai, Y., Suzuki, H., Kagiyama, N., Takakura, A. and Ghoda, A. 1989. Cross reactivity of Mycoplasma pulmonis and Mycoplasma arthritidis antigen strains to anti-Mycoplasma pulmonis antibody in the sera of Mycoplasma pulmonis infected rats. Kitasato Arch. Exp. Med. 62: 45-51. [Medline]

21. Lewis, M., Chang, G., Horton, N. C., Kercher, M. A., Pace, H. C., Schumacher, M. A., Brennan, R. G. and Lu, P. 1996. Crystal structure of the lactose operon repressor and its complexes with DNA and inducer. Science 271: 1247-1254. [Medline] [CrossRef]

22. Minion, F. C., Brown, M. B. and Cassell, G. H. 1984. Identification of cross-reactive antigens between Mycoplasma pulmonis and Mycoplasma arthritidis. Infect. Immun. 43: 115-121. [Medline]

23. Reyes, L., Shelton, M., Riggs, M. and Brown, M. B. 2004. Rat strains differ in susceptibility to maternal and fetal infection with Mycoplasma pulmonis. Am. J. Reprod. Immunol. 51: 211-219. [Medline] [CrossRef]

24. Reyes, L., Steiner, D. A., Hutchison, J., Crenshaw, B. and Brown, M. B. 2000. Mycoplasma pulmonis genital disease: effect of rat strain on pregnancy outcome. Comp. Med. 50: 622-627. [Medline]

25. Robino, P., Alberti, A., Pittau, M., Chessa, B., Miciletta, M., Nebbia, P., Le Grand, D. and Rosati, S. 2005. Genetic and antigenic characterization of the surface lipoprotein P48 of Mycoplasma bovis. Vet. Microbiol. 109: 201-209. [Medline] [CrossRef]

26. Rodriguez-Cuesta, J., Vidal-Vanaclocha, F., Mendoza, L., Valcarcel, M., Gallot, N. and Martinez de Tejada, G. 2005. Effect of asymptomatic natural infections due to common mouse pathogens on the metastatic progression of B16 murine melanoma in C57BL/6 mice. Clin. Exp. Metastasis 22: 549-558. [Medline] [CrossRef]

27. Rosati, S., Robino, P., Fadda, M., Pozzi, S., Mannelli, A. and Pittau, M. 2000. Expression and antigenic characterization of recombinant Mycoplasma agalactiae $\mathrm{P} 48$ major surface protein. Vet. Microbiol. 71: 201-210. [Medline] [CrossRef]

28. Saier, M. H. 2000. Families of transmembrane sugar transport proteins. Mol. Microbiol. 35: 699-710. [Medline] [CrossRef]

29. Shen, X., Gumulak, J., Yu, H., French, C. T., Zou, N. and Dybvig, K. 2000. Gene rearrangements in the vsa locus of Mycoplasma pulmonis. J. Bacteriol. 182: 2900-2908. [Medline] [CrossRef]

30. Steiner, D. A. and Brown, M. 1993. Impact of experimental genital mycoplasmosis on pregnancy outcome in Sprague-Dawley rats. Infect. Immun. 61: 633-639. [Medline]

31. Steiner, D. A., Uhl, E. and Brown, M. 1993. In utero transmission of Mycoplasma pulmonis in experimentally infected Sprague-Dawley rats. Infect. Immun. 61: 2985-2990. [Medline]

32. Won, Y. S., Jeong, E. S., Park, H. J., Lee, C. H., Nam, K. H., Kim, H. C., Hyun, B. H., Lee, S. K. and Choi, Y. K. 2006. Microbiological contamination of laboratory mice and rats in Korea from 1999 to 2003. Exp. Anim. 55: 11-16. [Medline] [CrossRef]

33. Zdobnov, E. M. and Apweiler, R. 2001. InterProScan-an integration platform for the signature-recognition methods in InterPro. Bioinformatics 17: 847-848. [Medline] [CrossRef] 